Proc. of the X Int. Conf. - Ion Implantation and other Applications of Ions and Electrons, Kazimierz Dolny 2014

\title{
Investigation of Nanoscale TiN/MoN Multilayered Systems, Fabricated Using Arc Evaporation
}

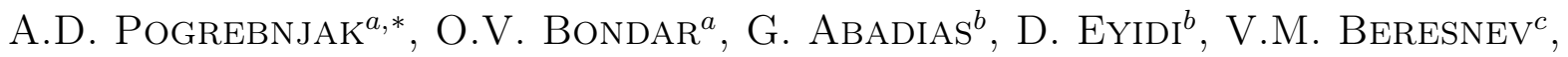 \\ O.V. Sobol ${ }^{d}$, B.O. Postolnyi ${ }^{a}$ And P. Zukowski ${ }^{e}$ \\ ${ }^{a}$ Sumy State University, 40007 Sumy, Ukraine \\ ${ }^{b} \mathrm{P}$ ' Institute, University of Poitiers, Poitiers, Futuroscope, France \\ ${ }^{c}$ Kharkiv National University, Kharkiv, Ukraine \\ ${ }^{d}$ National Technical University "KhPI", Kharkiv, Ukraine \\ ${ }^{e}$ Lublin University of Technology, Lublin, Poland
}

\begin{abstract}
Using the vacuum-arc evaporation method we fabricated periodic multilayered TiN/MoN structures with different bilayer periods $\lambda$ ranging from 8 to $100 \mathrm{~nm}$. We found that molybdenum nitride and titanium nitride layers grown on steel show local partial epitaxy and columnar growth across interfaces. A molybdenum-titanium carbide interlayer was evidenced between the substrate and the multilayer. Molybdenum nitride and titanium nitride layers contain small $(5 \div 30 \mathrm{~nm})$ grains and are well crystallized with (100) preferred orientation. They were identified as stoichiometric fcc TiN and cubic $\gamma-\mathrm{M}_{2} \mathrm{~N}$. Non-cubic molybdenum nitride phases were also detected. The hardness of the obtained structures achieved great values and maximal hardness was $31 \div 41.8 \mathrm{GPa}$ for the multilayered structure with a $8 \mathrm{~nm}$ period. Hardness of the obtained coatings is $25 \div 45 \%$ higher in comparison with the initial single-layer nitride coatings, plasticity index of multilayered structure is 0.075 .
\end{abstract}

DOI: 10.12693/APhysPolA.128.836

PACS: 61.46.--w, 62.20.Qp, 62.25.--g

\section{Introduction}

Refractory metals are widely used in modern materials science as basic elements for coatings with high functional properties, such as nitride coatings. Improving the properties of such coatings using multicomponent or multilayered systems is a very topical task nowadays.

Ion-plasma deposition or coating deposition using vacuum arc cathode evaporation seems to be a very promising way of fabrication of protective coatings [1-8]. In the presented paper we investigated TiN/MoN multilayered coatings with different bilayer periods from 8 to $100 \mathrm{~nm}$.

We should point out that multilayered, multicomponent and nanostructured coatings are widely used in modern materials science for increase of protective properties of different industrial products, and for improving their hardness, wear and corrosion resistance, oxidation resistance under the influence of high temperatures and so on $[4-10]$.

\section{Experimental procedure}

TiN/MoN samples were deposited on A 570 Grade 36 and AISI M2 high speed cutting steel substrates (steel disks of diameter not larger than $30 \mathrm{~mm}, 5 \mathrm{~mm}$ thickness, in a delivery state - these samples were used for tribotechnical tests) under different deposition regimes. A second series of substrates with $2 \mathrm{~mm}$ thickness and

*corresponding author; e-mail: alexp@i.ua
$20 \mathrm{~mm}$ diameter was used for the Rutherford backscattering spectrometry (RBS), scanning electron microscopy (SEM), energy dispersive X-ray spectroscopy (EDS), transmission electron microscopy (TEM), nano- and microhardness tests. Substrate surface was treated using glow discharge in order to clean and activate it before deposition. For the multilayer TiN/MoN coatings deposition we used a vacuum-arc device Bulat- 6 with two evaporators ( $\mathrm{Ti}$ and $\mathrm{Mo}$ ) [10], which allows deposition of nanostructured coatings in pulsed mode with variable pulse amplitude and pulse frequency. Figure 1 shows a scheme of the deposition system. The vacuum chamber (1) (base pressure of the chamber was $0.001 \mathrm{~Pa}$ ) was equipped with a system of automatic nitrogen pressure control (2) and two evaporators consisting of Mo (3) and Ti (4) (purity of metallic target was 99.8\%). The substrate holder (5) was mounted on a rotating stainless steel plate $\left(300 \times 300 \mathrm{~mm}^{2}\right)$ on which the substrates (6) were placed. BULAT- 6 was also equipped with the DC voltage source (7), the value of which can be varied between $5 \div 1000 \mathrm{~V}$, and the high-voltage impulse generator (8) with the adjustable voltage pulse amplitude of $0.5 \div 2 \mathrm{kV}$ and the repetition frequency of $5 \div 7 \mathrm{kHz}$. The substrates cleaning process was carried out using molybdenum ions for $3 \div 5 \mathrm{~min}$, while applying a $1 \mathrm{kV}$ substrate potential. Further, nitrogen was injected into the chamber and nitrides of titanium and molybdenum were deposited on opposite substrate sides. When the first layers had been finished, deposition stopped and substrates turned over at the angle of $180^{\circ}$. Then deposition started again. In this way, the average deposition speed was $1 \div 2 \mathrm{~nm} / \mathrm{s}$. The arc current was $95 \div 100$ A during deposition, nitro- 
gen pressure in the chamber was $0.5 \mathrm{~Pa}$, the distance between the evaporator and the substrate was $250 \mathrm{~mm}$ and the substrate temperature was $250 \div 350^{\circ} \mathrm{C}$. During deposition of coatings a pulsed potential of $-40 \mathrm{~V}$ (with duration of $10 \mu \mathrm{s}$, repetition frequency $7 \mathrm{kHz}$ ) was applied to the substrate. The bilayer period $\lambda$ of the multilayer coating varied between 8 and $100 \mathrm{~nm}$ by changing the deposition time under fixed deposition conditions (see the Table). The total thickness of the multilayered coatings was $6.8-8.2 \mu \mathrm{m}$.

Parameters of coating deposition.

TABLE

\begin{tabular}{c|c|c|c|c|c|c|c|c|c}
\hline \hline \multirow{2}{*}{$\#$} & \multirow{2}{*}{ material } & \multicolumn{2}{|c|}{ period $\lambda[\mathrm{nm}]$} & \multirow{2}{*}{$i[\mathrm{a}]$} & \multirow{2}{*}{ time $[\mathrm{s}] \mathrm{Ti} / \mathrm{Mo}$} & \multirow{2}{*}{$U_{\text {bias }}[\mathrm{V}]$} & \multirow{2}{*}[\mathrm{V}]{} & \multirow{2}{*}{ Pulse freq. $[\mathrm{kHz}]$} & \multirow{2}{*}[\mathrm{Pa}]{} \\
\cline { 3 - 7 } & & Expect. & Meas. & & & & & & \\
\hline 1 & TiN/MoN & 5 & $8 \pm 0.05$ & 90 & $3 / 3$ & -40 & 1000 & 6 & 0.5 \\
\hline 2 & TiN/MoN & 20 & $25 \pm 1.5$ & $95 \div 100$ & $10 / 10$ & -40 & 1000 & 7 & 0.5 \\
\hline 3 & TiN/MoN & 40 & $50 \pm 2.2$ & $95 \div 100$ & $20 / 20$ & -40 & 1000 & 7 & 0.5 \\
\hline 4 & TiN/MoN & 80 & $100 \pm 3.8$ & $95 \div 100$ & $40 / 40$ & -40 & 1000 & 7 & 0.5
\end{tabular}

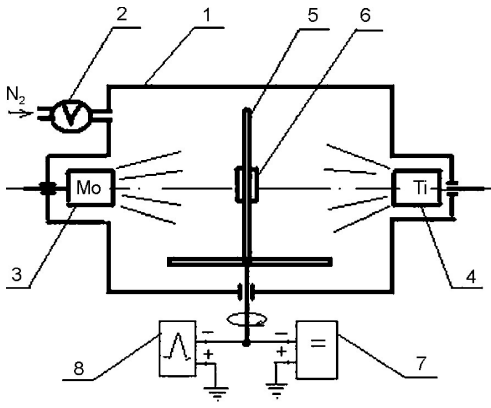

Fig. 1. Schematic representation of the "BULAT-6" deposition system (1 - vacuum chamber; 2 - automatic control system of the nitrogen pressure; 3 molybdenum evaporator; 4 - titanium evaporator; 5 — substrate holder; 6 - substrate; 7 - DC voltage source; 8 - high-voltage impulse generator).

To obtain full information about element composition of the coatings, the RBS technique was used. The $\mathrm{He}^{+}$ ion beam energy was fixed at $1.5 \mathrm{MeV}$ the other experimental parameters being: normal incidence of ions, the scattering angle $\theta=170^{\circ}$, He ions dose of $5 \mu \mathrm{C}$ and a detector energy resolution of $16 \mathrm{keV}$.

Microstructure and element composition investigations were carried out using several SEM: Quanta 200 3D, Quanta 600 FE-SEM equipped with a PEGASUS 2000 X-ray detector, and a JEOL-7001F-TTLS with the microanalysis EDS unit. Depth profile analysis was done using $500 \mathrm{nA}, 1.72 \mathrm{keV} \mathrm{Ar}^{+}$primary ion beam at $45^{\circ}$ incidence angle. SAJW-05 SIMS analyser was equipped with a Physical Electronics 06-350E ion gun and QMA410 Balzers quadrupole mass analyser with $16 \mathrm{~mm}$ diameter rods. Structure and phase composition were studied by X-ray diffraction (XRD) using a Bruker Advanced D8 goniometer operating in the Bragg-Brentano configuration with $\mathrm{Cu} K_{\alpha}$ radiation. Diffraction profiles allocation in the case of peak overlap was done using the computer program "New profile" (Ukrainian National Technical University "KhPI"). Volume fraction of phases in the coating was calculated using the standard method, taking $X$ integral intensity into account.
The samples grown on steel were also investigated by cross-sectional TEM (XTEM) in high-resolution, brightfield, dark-field and selected area electron diffraction (SAED) modes using a JEOL 2200-FS equipped with a field-emission gun and an omega energy filter. Images and diffraction patterns were filtered with a $10 \mathrm{eV}$ slit width around the zero-loss peak. Chemical mapping was made on a JEOL-2100 LaB6 machine equipped with a Jeol EDS system. Both TEMs were operated at $200 \mathrm{kV}$. Measurements of hardness and Young modulus were done using instrumented microhardness CSM REVETEST apparatus (Switzerland). Tribological tests were done using a CSM Instruments tribometer. To provide such tests a probe was placed on the test sample and loaded with a precisely known weight. The sample was either rotating or reciprocating in a linear track. The resulting frictional forces acting between the probe and the sample were measured. Additionally, the wear for both the sample and probe was calculated from the volume of the material lost during the term of the test.

\section{Results and discussion}

The elemental composition of the samples was determined by RBS as well as EDS on the cross-sectional images. The RBS spectrum for TiN/MoN coatings with $\lambda=50 \mathrm{~nm}$ is presented in Fig. 2a. We can see kinematic factors for $\mathrm{Ti}$ and Mo near the surface, as well as "modulations" and we can estimate the thickness of individual layer from them. Therefore, choosing the number of channels and knowing ion loss per one channel an average thickness of the layer on the cross-section of the analyzing beam can be calculated. It can be stated that the thickness of MoN layer equals $16.2 \mathrm{~nm}$. Using the RBS spectrum data one can estimate thickness of the first four layers from the surface, and it should be stressed that the thickness of TiN layer is $\approx 33.8 \mathrm{~nm}$, which is twice as much as the thickness of MoN layer. The results of SIMS analysis of the TiN/MoN coating with $\lambda=50 \mathrm{~nm}$ are presented in the inset of Fig. 2a. Taking into account ion energy loss, detector resolution and the etching rate of Ar ions, a value of $\lambda=48.7 \mathrm{~nm}$ is obtained which 


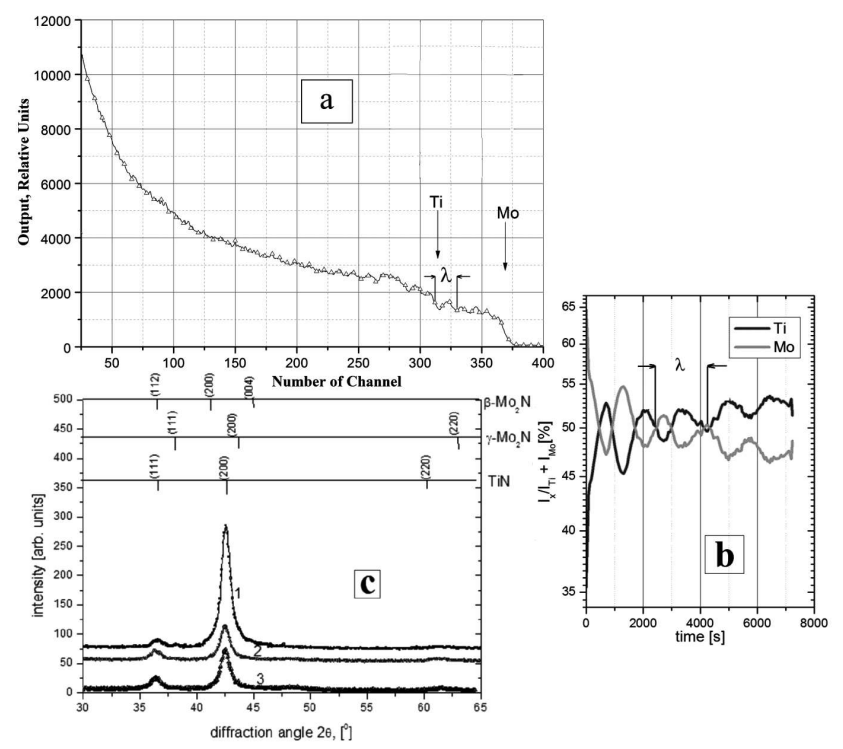

Fig. 2. a - RBS spectrum of $4 \mathrm{He}^{+}$ions backscattering for sample 2 in the Table with TiN/MoN coating, logarithmic scale is to the left; $\mathrm{b}$ - SIMS depth profile analysis of normalized secondary ion currents: $m / z=48$ $\left(\mathrm{Ti}^{+}\right)$and $98\left(\mathrm{Mo}^{+}\right) ; \mathrm{c}-\mathrm{XRD}$ patterns for coatings with different bilayer periods $(\lambda=25 \mathrm{~nm}$ - curve 1 , $\lambda=50 \mathrm{~nm}-$ curve 2 and $\lambda=100 \mathrm{~nm}$ - curve 3$)$.

is in good agreement with the RBS data and the SEM observations.

The XRD patterns of the TiN/MoN multilayers with $\lambda=25,50$ and $100 \mathrm{~nm}$ are reported in Fig. 2c. Two main reflections are observed around $2 \theta=36.5$ and $42.5^{\circ}$. The peak at $2 \theta=36.5$ is attributed to (111)-oriented TiN grains. These results suggest that the TiN/MoN multilayers consist of highly-textured (200) cubic layers compared to the intensity ratio expected for bulk polycrystalline reference powders [11-13].

Volume fraction of TiN and $\gamma-\mathrm{Mo}_{2} \mathrm{~N}$ phases was extracted from the XRD line fitting procedure of the (200) peak using the "New_profile" software. For $\lambda=25 \mathrm{~nm}$, a $\mathrm{TiN} / \gamma-\mathrm{Mo}_{2} \mathrm{~N}$ ratio of $90 / 10$ is obtained. Increase of the period of $\mathrm{TiN} / \mathrm{MoN}$ layers up to $50 \mathrm{~nm}$ led to forming two-phase structure with an average content of TiN and $\gamma-\mathrm{Mo}_{2} \mathrm{~N}$ cubic phases equal to 60 vol. $\%$ and 40 vol. $\%$, which correlates with $\mathrm{Ti}$ and Mo concentrations, obtained using EDX, equal to 62.3 at. $\%$ and 36.8 at. $\%$ accordingly. For the samples with thicker TiN and $\mathrm{Mo}_{2} \mathrm{~N}$ layers $(\lambda \approx 100 \mathrm{~nm})$ volume fraction of phases corresponds to the EDX analysis data - 70 at.\% for TiN and 30 at. $\%$ for $\mathrm{Mo}_{2} \mathrm{~N}$.

It should be noted that in the molybdenum nitride layers only $\gamma-\mathrm{Mo}_{2} \mathrm{~N}$ with cubic, $\mathrm{Na}-\mathrm{Cl}$ type lattice was formed while the $\beta-\mathrm{Mo}_{2} \mathrm{~N}$ phase (tetragonal lattice) cannot be seen using XRD despite the fact that both phases can be formed in the case of coating deposition using the vacuum-arc method and magnetron sputtering. It can be explained by the two-stage process of forma- tion of phase composition of the multilayered coating. In the early growth stage, a template effect occurs due to small lattice mismatch $(<2 \%)$ between cubic TiN $\left(a_{\mathrm{TiN}}=0.4242 \mathrm{~nm}\right.$, see JCPDS file no. 38-1420) and cubic $\mathrm{Mo}_{2} \mathrm{~N}\left(a_{\mathrm{Mo} 2 \mathrm{~N}}=0.4163 \mathrm{~nm}\right.$, see JCPDS file no. 25-1366) phases, promoting the stabilization of $\gamma-\mathrm{Mo}_{2} \mathrm{~N}$ cubic modification by atomic registry [14].

The cross-section SEM micrographs of the nanostructured coating are presented in Fig. 3a, alternating nanoscale layers can be easily seen in Fig. 3b, the dark layers correspond to TiN, the bright ones correspond to MoN.

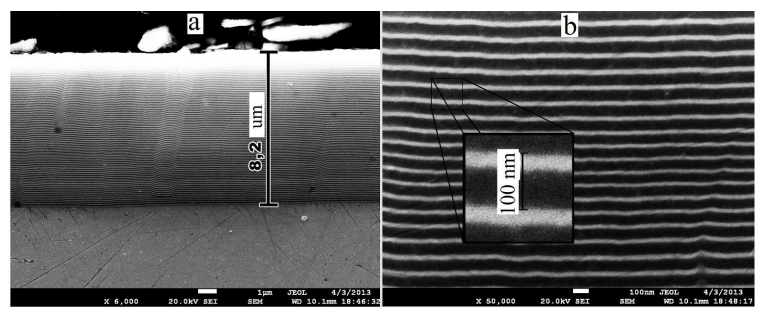

Fig. 3. Cross-sectional SEM micrograph of TiN/MoN multilayer coating with $\lambda=100 \mathrm{~nm}$ : a - general view, thickness is $8.2 \mu \mathrm{m}$; b - higher magnification (x 50000 ) showing individual layer thickness.

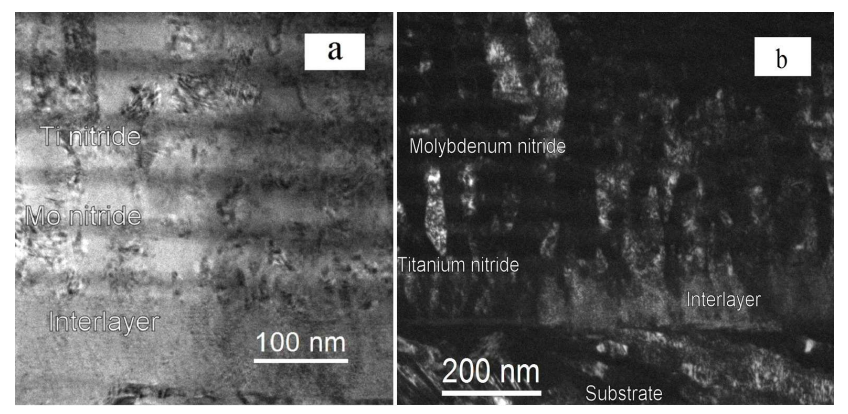

Fig. 4. TEM bright field (a) and dark field (b) images showing the substrate, the interlayer and the TiN and MoN layers.

High resolution microscopy (HR-TEM) was used to characterize the structure of the multilayered system with the $\lambda=50 \mathrm{~nm}$ average period. The TEM brightfield and dark-field images in Fig. 4 show columnar growth of the multilayer nitride system. It starts with the interface between the $\{111\}$ textured steel substrate and the multilayer, or from within the multilayer.

Slightly bent grains extend across the nitride layers and interfaces, and are $20 \div 100 \mathrm{~nm}$ large and $100 \div 500 \mathrm{~nm}$ long. A $100 \mathrm{~nm}$ thin interlayer is visible and contains $\mathrm{Ti}$, Mo, $\mathrm{C}$ and traces of $\mathrm{N}$ as evidenced by the EDS mapping. This interlayer does not show any texture, is well crystallized and also contains columnar grains. A structural modulation with a period $\approx 5 \mathrm{~nm}$ can be seen within the interlayer, as shown in the bright-field and fast-Fouriertransform (FFT) images in Fig. 5. This type of modulation was observed in several metallic carbides which contain Ti or Mo and exhibit a superstructure due to the incorporation of impurity atoms in the lattice. 

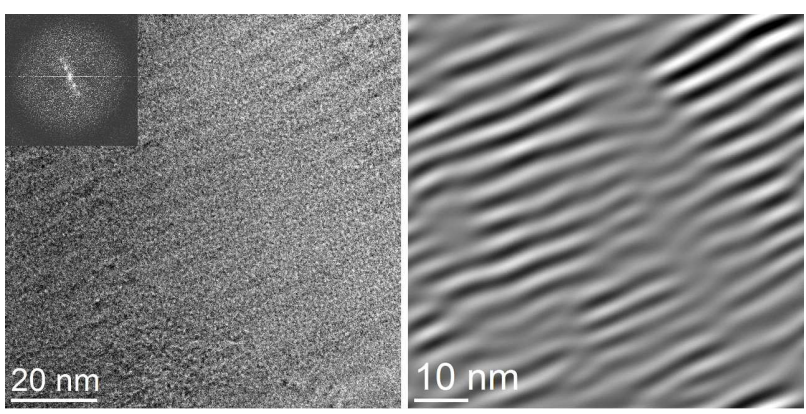

Fig. 5. TEM bright-field (a) and FFT-filtered image (b) of the interlayer grown between the substrate and the multilayer. The FFT in shown in inset.

The first layer grown on top of this interlayer is a $5 \mathrm{~nm}$ thin titanium nitride, then followed by a $20 \mathrm{~nm}$ molybdenum nitride and a $40 \mathrm{~nm}$ titanium nitride again (see Fig. 4). The sequence was then repeated until the multilayer reached a total thickness of about $8 \mu \mathrm{m}$. It was reported that $(\mathrm{Mo}, \mathrm{Ti}) \mathrm{C}$ compound is fcc with a lattice parameter $a \approx 0.426 \mathrm{~nm}$. The mismatch with TiN being close to zero, which allows for local epitaxy $(111)_{\mathrm{MoTiC}} / /(111)_{\mathrm{TiN}}$.

A typical diffraction pattern from the multilayer is shown in Fig. 6a. Here an area encompassing about 10 alternating layers was selected. The spots randomly distributed on circles labelled from 1 to 5 indicate layers of polycrystalline character. All spots in this diffraction pattern could be indexed with reflections belonging to fcc TiN and cubic $\gamma-\mathrm{Mo}_{2} \mathrm{~N}$. Adjacent circles no. 1 and 2 cross 111 spots and bear witness for local lattice parameter variation of about $2-3 \%$ within the nitride layers, so do circles 4 and 5 which cross 220 spots, while circle 3 goes through 200 spots. In the high-resolution TEM image shown in Fig. 6b, both titanium and molybdenum nitride layers appear well crystallized with thicknesses of $40 \pm 5 \mathrm{~nm}$ and $20 \pm 5 \mathrm{~nm}$, respectively. Partial epitaxy occurs between the adjacent $\mathrm{Mo}_{2} \mathrm{~N}$ and TiN layers. Randomly oriented and distributed Moiré patterns extending over a few $\mathrm{nm}$ are frequently observed, especially in the molybdenum nitride layers. All layers are only weakly textured (if at all) with $\{100\}$ orientation seen more frequently than $\{111\}$. The titanium nitride layers contain $5 \div 30 \mathrm{~nm}$ size grains and are unambiguously identified as stoichiometric TiN. From most HRTEM images of the molybdenum nitride layers, all of which are fine grained $(5 \div 10 \mathrm{~nm}$ size $)$, a good match was found with $\gamma-\mathrm{Mo}_{2} \mathrm{~N}$. However, in some cases FFTs reveal interplanar distances corresponding to non-cubic molybdenum nitrides - possibly strongly distorted $\mathrm{Mo}_{2} \mathrm{~N}$ or tetragonal $\mathrm{Mo}_{2} \mathrm{~N}$ - as reported by other authors [15]. FFTs acquired at few $\mu \mathrm{m}$ from the substrate in the molybdenum nitride layer, showed some SAED spots (such as one yielding an interplanar distance of $0.185 \mathrm{~nm}$ ) that were consistent with 02-22 reflection from hexagonal MoN. The main reason for two-phase state appearing was intensive ion bombard-
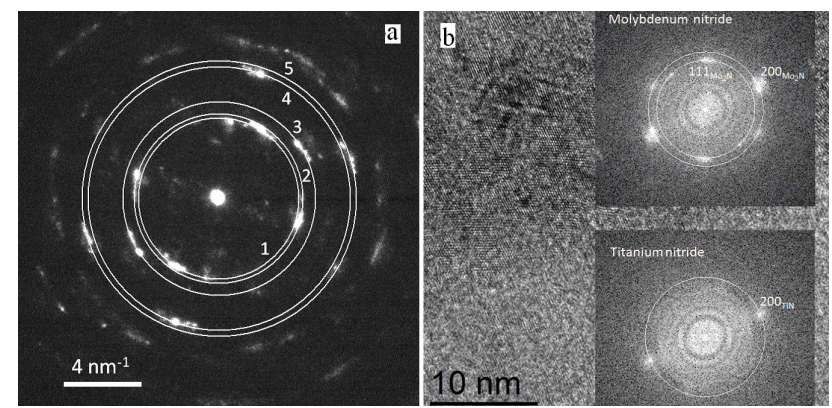

Fig. 6. SAED pattern from the multilayer (a) and FFTs from the HRTEM images of the titanium and molybdenum nitride layers (b).

ment, which led to nanograins grinding and forming of interphase boundaries. Separate $\gamma-\mathrm{Mo}_{2} \mathrm{~N}$ layers with cubic lattice were formed and it caused interphase boundary formation.

We investigated mechanical characteristics using the nanoindentation method and we found that the largest hardness of $\approx 41.8 \mathrm{GPa}$ was achieved for $\lambda=8 \mathrm{~nm}$ period multilayered coating. Increase of the period to $100 \mathrm{~nm}$ or decrease to $25 \mathrm{~nm}$ led to decrease of the hardness to the value of $26 \mathrm{GPa}$, which is rather similar to that of the single-layered TiN coating (about $23 \mathrm{GPa}$ ). Maximum value of the elasticity modulus $E=456 \mathrm{GPa}$ corresponds to $\lambda=25 \mathrm{~nm}$, and its value decreases with the increasing period.

Thus, the obtained multilayered coatings have large hardness, which is more than $25 \%$ higher than that of composing nitrides. The plasticity index, which is defined as the hardness $(H)$ to elasticity modulus $(E)$ ratio $H / E$ [7-10], is also rather high and exceeds the value 0.06 . It allows using such coatings as protective under the influence of different alternating loadings and abrasive wear $[7,16-18]$. For the multilayered TiN/MoN system we found that the lowest value of $L_{\mathrm{c} 3}$ critical loading was $42.5 \mathrm{~N}$, and it corresponds to the periodic structure with the biggest period of $100 \mathrm{~nm}$. If the period was $50 \mathrm{~nm}$, this critical loading value increased up to $61.0 \mathrm{~N}$, and for the smallest $25 \mathrm{~nm}$ period $L_{\mathrm{c} 3}$ reached $64.8 \mathrm{~N}$. Thus, using very thin layers in the multilayered system leads to the increasing specific density of interphase boundaries per volume unit, in turn, it leads to the increasing critical loading of destruction.

\section{Conclusions}

Using the C-PVD method multilayered TiN/MoN coatings with different $8,25,50$ and $100 \mathrm{~nm}$ layer size were fabricated. For such coatings it was found that maximal hardness and elasticity modulus were observed for $8 \mathrm{~nm}$ and $25 \mathrm{~nm}$ period, respectively. The lowest value of critical loading was $42.5 \mathrm{~N}$, which corresponds to the periodic structure with the biggest period of $100 \mathrm{~nm}$. If the period was $50 \mathrm{~nm}$, the critical loading value increased up to $61.0 \mathrm{~N}$, and for the smallest $25 \mathrm{~nm}$ period critical load reached $64.8 \mathrm{~N}$. Thus, using very thin layers in the 
multilayered system leads to the increase of specific density of interphase boundaries per volume unit and to the increase of critical loading of destruction.

\section{Acknowledgments}

This work was done under the aegis of scientifictechnical collaboration program between the Sumy State University (Sumy, Ukraine) and University of Poitiers (Institut P', University of Poitiers, Poitiers, France), and the Ukrainian complex state budget programs "Creation of basis of superhard nanostructure coatings fabrication with high physical and mechanical properties" (registration number 0112U001382) and "Physical principles of plasma technologies for complex treatment of multicomponent materials and coatings" (registration number 0113U000137c).

The authors are grateful to Prof. F.F. Komarov for his help in providing RBS analysis, A.A. Andreev for his help in coatings fabrication, Prof. P. Chartier for his help in microindentation measurements and to Prof. P. Konarski for his help in SIMS measurements.

\section{References}

[1] Q. Meng, M. Wen, P. Liu, K. Zhang, W. Zheng, Mater. Lett. 94, 61 (2013).

[2] G. Abadias, Ph. Guerin, Appl. Phys. Lett. 93, 111908 (2008).

[3] H. Soderberg, M. Oden, T. Larsson, L. Hultman, J.M. Molina-Aldareguia, Appl. Phys. Lett. $\mathbf{8 8}$ 191902 (2006).

[4] A.D. Pogrebnjak, A.G. Ponomarev, A.P. Shpak, Yu.A. Kunitskii, Phys. Usp. 55, 270 (2012).
[5] A.D. Pogrebnjak, S.N. Bratushka, V.I. Boyko, I.V. Shamanin, Yu.V. Tsvintarnaya, NIM B 145, 373 (1998).

[6] M. Nordin, M. Larsson, S. Hogmark, Surf. Coat. Technol. 106, 234 (1998).

[7] J. Musil, Surf. Coat. Technol. 207, 50 (2012).

[8] I.N. Martev, D.A. Dechev, N.P. Ivanov, Ts.D. Uzunov, E.P. Kashchieva, J. Phys. Conf. Series 223, 012 (2010).

[9] A.D. Pogrebnjak, A.P. Shpak, N.A. Azarenkov, V.M. Beresnev, Phys. Usp. 52, 29 (2009).

[10] A.D. Pogrebnjak, V.M. Beresnev, Nanocoatings Nanosystems Nanotechnologies, Bentham Sci. Publ., UAE 2012, p. 147.

[11] G. Abadias, V.I. Ivashchenko, L. Belliard, Ph. Djemia, Acta Mater. 60, 5601 (2012).

[12] U. Welzel, J. Ligot, P. Lamparter, A.C. Vermeulen, E.J. Mittemeijer, J. Appl. Crystallogr. 38, 1 (2005).

[13] J.-D. Kamminga, Th.H. de Keijser, R. Delhez, E.J. Mittemeijer, J. Appl. Phys. 88, 6332 (2000).

[14] COMPTECH JCPDS database.

[15] D. Machon, D. Daisenberger, E. Soignard, E. Shen, T. Kawashima, E. Takayama-Muromachi, P.E. McMillan, Phys. Status Solidi A 203, 831 (2006).

[16] A.D. Pogrebnjak, J. Nanomater. 2013, 780125 (2013).

[17] A.D. Pogrebnjak, G. Abadias, O.V. Bondar, B.O. Postolnyi, M.O. Lisovenko, O.V. Kyrychenko, A.A. Andreev, V.M. Beresnev, D.A. Kolesnikov, M. Opielak, Acta Phys. Pol. A 125, 1280 (2014).

[18] A.D. Pogrebnjak, V.M. Beresnev, O.V. Bondar, G. Abadias, P. Chartier, B.A. Postolnyi, A.A. Andreev, O.V. Sobol, Tech. Phys. Lett. 40, 215 (2014). 